\title{
Applicability of RNA standards for evaluating RT-qPCR assays and platforms
}

\author{
Alison S Devonshire, Ramnath Elaswarapu*, Carole A Foy
}

\begin{abstract}
The availability of diverse RT-qPCR assay formats and technologies hinder comparability of data between platforms. Reference standards to facilitate platform evaluation and comparability are needed. We have explored using universal RNA standards for comparing the performance of a novel qPCR platform (Fluidigm ${ }^{\circledR}$ BioMark ${ }^{\mathrm{TM}}$ ) against the widely used $\mathrm{ABI} 7900 \mathrm{HT}$ system. Our results show that such standards may form part of a toolkit to evaluate the key performance characteristics of platforms.
\end{abstract}

\section{Background}

Reverse transcription quantitative PCR (RT-qPCR) is rapidly becoming a valuable tool for mRNA biomarker quantification in clinical diagnostics. There has been a proliferation of RT-qPCR assay formats and platforms in recent years due to wider applications of this technology, coupled with improvements in sensitivity, specificity and accuracy of measurements of gene expression. However, there is one intrinsic limitation to the current qPCR platforms, namely lack of controls for crossplatform comparison. Although the manufacturers have developed platform-specific quality controls, they are often not adequate for cross-platform comparisons, particularly for the evaluation and standardization of transcriptomic data due to differences in protocols, data processing and analysis methods. Thus, development of universal RNA standards offers great potential in the validation of data obtained from different RT-qPCR methods. In the present investigation, we have compared the performance of Fluidigm ${ }^{\circledR}$ BioMark ${ }^{\mathrm{TM}}$ Integrated microfluidic (henceforth referred to as BioMark) dynamic arrays with the widely used ABI 7900HT realtime PCR platform (henceforth called ABI 7900HT system) using generic RNA standards.

Pre-amplification of RNA or cDNA facilitates the investigation of a large number of genes when the starting material is limiting, such as with tissue biopsies and archival formalin-fixed paraffin-embedded (FFPE) samples $[1,2]$. Pre-amplification methods used generally include

\footnotetext{
* Correspondence: ramnath.elaswarapu@lgc.co.uk

LGC Limited, Queens Road, Teddington, Middlesex, TW11 OLY, UK
}

either linear amplification of RNA or exponential (PCRbased) amplification of cDNA [3-5]. However, concerns have been raised as to whether pre-amplification of samples by exponential amplification introduces bias in expression levels between genes [6]. For the BioMark microfluidic PCR system, each sample in the $48 \times 48$ dynamic array is distributed amongst 48 different reaction chambers, therefore pre-amplification is recommended for certain applications. However the limit of detection (LOD) of using pre-amplified $v s$. non-amplified cDNA samples, and its impact on the technical performance of the PCR array have not been fully characterized.

Exogenous RNA controls produced by in vitro transcription are ideal materials for investigating different RT-qPCR kits and methodologies [7]. Recently a panel of RNA controls have been developed for use in gene expression applications by the External RNA Controls Consortium (ERCC), an ad hoc group of 70 members from private, public and academic organizations led by the National Institute of Standards (NIST) $[8,9]$. It is hoped that standards developed from these sequences will aid in comparisons of gene expression data generated from various platforms such as microarray, RTqPCR and next generation sequencing, and also provide quality control of gene expression measurements in the clinical laboratory [10]. Multigene biomarker measurements are at the forefront of a new class of medical devices using in vitro diagnostic multivariate assays, such as MammaPrint and Oncotype Dx in the area of breast cancer prognosis [11]. Since gene expression biomarkers typically encompass a range of transcript abundances and differential expression ratios, it is more 
appropriate to use multiple RNA standards as quality controls for standardizing such measurements, as opposed to a single transcript at a fixed concentration.

In the current study, we used a sub-set of the 96 ERCC RNA standards (Additional File 1) in order to characterize their performance on a nanofluidic PCR system, the BioMark $48 \times 48$ dynamic arrays, against a conventional qPCR platform, the ABI $7900 \mathrm{HT}$ system. We also investigated the impact of pre-amplification of cDNA samples on the linear range and precision of measurements by nanofluidic qPCR. Two prototype panels were constructed with selected RNA standards containing varying copy number within each panel, and varying ratios between them for mimicking non-differentially and differentially expressed mRNA biomarkers as represented in normal and disease states. The expression profile of the RNA standards was measured using both platforms and the accuracy and precision of their detection were compared.

\section{Results}

\section{Linear range of dynamic arrays}

One advantage of the BioMark arrays is the capability to analyse a large number of genes in a single sample. In order to facilitate this, up to $\sim 2 \mu \mathrm{L}$ of sample is loaded into each sample inlet of the chip and further distributed in the channels of the microfluidic chip as 48 separate $9 \mathrm{~nL}$ reactions using the integrated fluidic circuit (IFC). Thus the original sample is diluted more than 200 -fold prior to the PCR reaction. In order to ensure that there are sufficient copies of target molecules in each reaction, Fluidigm ${ }^{\circledR}$ recommends using either RNA samples that do not have a concentration lower than $250 \mathrm{ng}$ total $\mathrm{RNA} / \mu \mathrm{L}$ or that a pre-amplification stage is included, whereby the cDNA sample undergoes 14-18 cycles of amplification with a mix of up to 100 different primer pairs (Fluidigm Advanced Development Protocols 3, 5 and 8). In order to further investigate the requirement for pre-amplification, RNA standards were spiked into human total RNA at different concentrations (for sample composition, see Additional File 2) with the aim of mimicking a range of physiological abundances, from highly abundant mRNA transcripts $\left(10^{6}\right.$ copies/ng total RNA; equivalent to $10^{4}$ copies per cell) to transcripts only expressed in a sub-population of cells (1 copy/ng total RNA; equivalent to 0.01 copies per cell), based on the RNA content of a cell estimated as $26 \mathrm{pg}$ [12]. A single RT reaction was performed for each RNA sample followed by 3 independent qPCR runs, with replicate assay measurements for each ERCC standard.

Figure 1 compares the results of real-time PCR with cDNA samples (equivalent to 1 ng total RNA) or preamplified cDNA on the BioMark arrays with non-amplified cDNA using the ABI 7900HT system. The linear range in terms of transcript copy numbers for the pre-amplified cDNA samples on the BioMark arrays was similar to the non-amplified cDNA samples on the ABI 7900HT system, covering five orders of magnitude between 10 and $10^{6}$ copies/ng total RNA. Although the linear range of both platforms was similar, the Ct values from BioMark were over 10 units lower than those observed for ABI 7900HT system. This could be due to the higher concentration of the template in the $9 \mathrm{~nL}$ nanofluidic reaction chambers of BioMark arrays compared to the standard $20 \mu \mathrm{L}$ volume used on the ABI 7900HT system, such that the fluorescence output of the PCR reaction exceeds the threshold level at an earlier cycle (personal communication: A. Meliss, Fluidigm, September 2009). For the RT-PCRs performed with non-amplified cDNA samples on BioMark arrays, the linear detection range covered only two orders of magnitude between the transcript numbers of $10^{4}$ and $10^{6}$ copies/ng.

\section{LOD of dynamic arrays}

Unlike hybridization-based technologies such as microarrays, the LOD cannot be ascribed for RT-qPCR using a baseline for sample blanks, as a $\mathrm{Ct}$ value is not obtained for zero control samples. Therefore, the incidence of failed PCR reactions (undetermined $\mathrm{Ct}$ value) across the range of transcript abundances was also compared for conventional and nanofluidic PCR platforms with pre- or non-amplified cDNA as the template (Figure 2). As in Figure 1, a high percentage of PCR failures was observed at 1 copy/ng total RNA for both pre-amplified cDNA on the BioMark arrays and cDNA using the ABI 7900HT system. The rate of failures was slightly lower on the BioMark arrays as the projected template concentration per $9 \mathrm{~nL}$ reaction was 6 copies (assuming 100\% efficiency of RT and pre-amplification), whilst it was only 1 RNA copy per ABI 7900HT reaction. For non-amplified cDNA, high reaction failure rates with BioMark arrays were observed below $10^{3}$ copies/ng, which equates to 2 copies per $9 \mathrm{~nL}$ reaction.

\section{qPCR accuracy and precision}

The accuracy and precision of qPCR detection across the above noted linear range was assessed by linear regression, comparing the slope and $\mathrm{R}^{2}$ of the data from three independent dynamic arrays (Table 1). Pre-amplification of cDNA samples resulted in a significant improvement in the slope of the linear regression of copy number against $C$ value $(p<0.05)$, with the mean slope within $6 \%$ of the ideal slope of 1 . The pre-amplified cDNA samples demonstrated greater precision of the instrument over the linear detection range (Figure 1 ) than cDNA $(p<0.05)$ (Table 1$)$. The accuracy and precision of pre-amplified cDNA detection on the BioMark arrays 

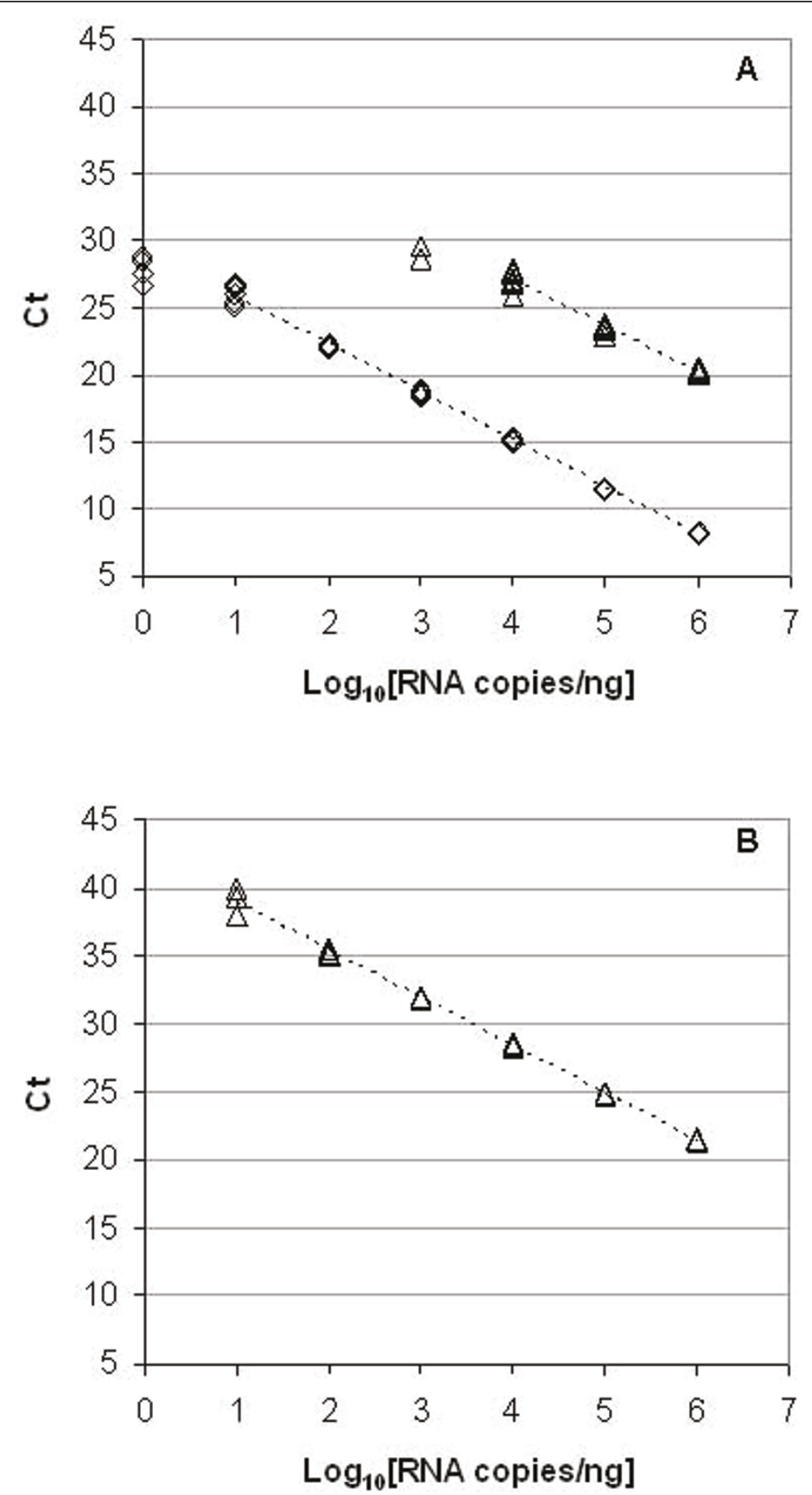

Figure 1 Linear range of RT-qPCR platforms. Example plot showing detection of an ERCC RNA standard (ERCC-42) across a range of transcript copy numbers from 1 to $10^{6}$ copies per ng total RNA with CDNA (triangles) or pre-amplified CDNA (diamonds) as the template on (A) BioMark (B) ABI 7900HT system. Data-points are displayed as individual GPCR replicates. Dotted line indicates linear detection range.

were comparable to those of the ABI $7900 \mathrm{HT}$ where non-amplified cDNA was used as the template (Table 1).

Precision of qPCR detection as a function of transcript copy number for the two platforms is shown in Figure 3. For concentrations of RNA standards above $10^{4}$ copies/ ng (using cDNA with the ABI 7900HT system or preamplified cDNA for the BioMark arrays), and above $10^{6}$ copies/ng (with non-amplified cDNA for the BioMark arrays), Ct standard deviation values are below 0.1 units, corresponding to less than $7 \%$ variation [13]. As RNA 


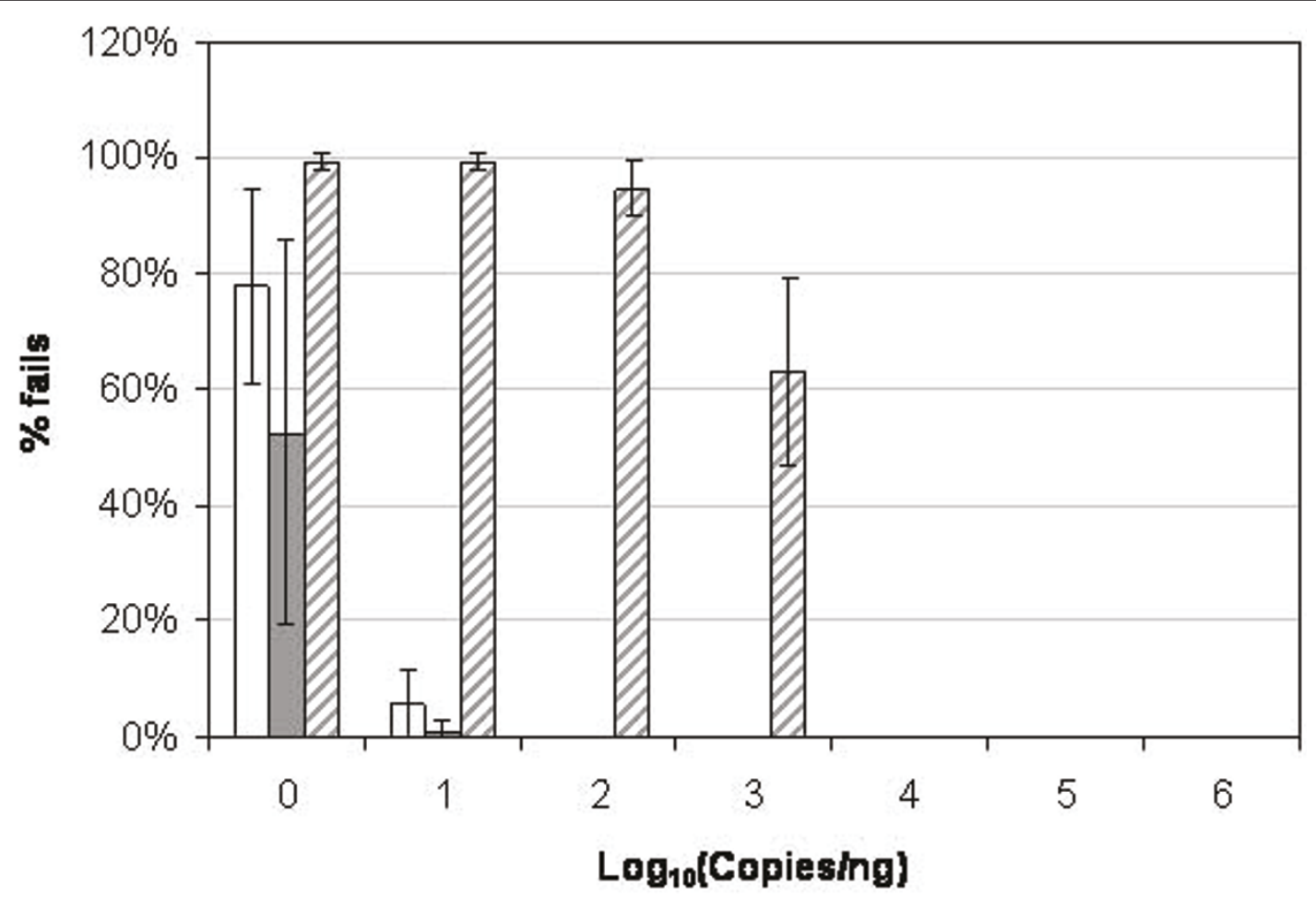

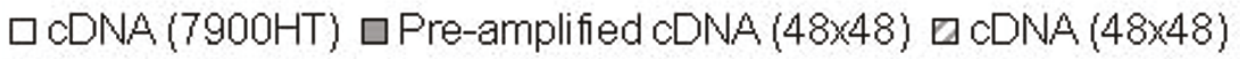

Figure 2 Limit of detection of ERCC RNA standards. Incidence of failed PCR reactions on ABI 7900HT system or BioMark using cDNA or preamplified CDNA as the template. Mean percentage of failed PCR reactions \pm SD are displayed based on data from 8 different RNA standards from 3 independent qPCR experiments across a range from 1 to $10^{6}$ copies ERCC standard per ng total RNA.

copy numbers decrease, variation between replicate qPCR measurements increases, with maximum average standard deviation values corresponding to $46 \%$ and $66 \%$ variation at 10 copies/ng for the BioMark arrays (preamplified cDNA) and ABI 7900HT system respectively (Figure 3).

\section{RNA biomarker panels}

The accuracy of nanofluidic dynamic PCR for detection of multiple genetic biomarkers was further tested using two panels of RNA standards. With the aim of mimicking 'normal' and 'disease' states where some biomarkers are differentially expressed whilst others remain

Table 1 Accuracy and precision of linear detection range of PCR platforms

\begin{tabular}{|c|c|c|c|c|c|c|}
\hline \multirow{3}{*}{$\begin{array}{l}\text { Platform } \\
\text { Template }\end{array}$} & \multicolumn{3}{|c|}{ Slope } & \multicolumn{3}{|c|}{$\mathrm{R}^{2}$} \\
\hline & \multicolumn{2}{|c|}{ Dynamic arrays } & \multirow{2}{*}{$\frac{\mathrm{ABI} 7900 \mathrm{HT}}{\mathrm{cDNA}}$} & \multicolumn{2}{|c|}{ Dynamic arrays } & \multirow{2}{*}{$\frac{\mathrm{ABI} 7900 \mathrm{HT}}{\mathrm{CDNA}}$} \\
\hline & $\begin{array}{c}\text { Pre-amplified } \\
\text { cDNA }\end{array}$ & cDNA & & $\begin{array}{c}\text { Pre-amplified } \\
\text { cDNA }\end{array}$ & cDNA & \\
\hline \multicolumn{7}{|l|}{ ERCC- } \\
\hline 13 & -1.06 & -1.08 & -1.06 & 0.999 & 0.993 & 0.997 \\
\hline 42 & -1.07 & -1.11 & -1.06 & 0.998 & 0.970 & 0.995 \\
\hline 81 & -1.02 & -1.07 & -1.04 & 0.998 & 0.976 & 0.998 \\
\hline 84 & -1.03 & -1.07 & -1.01 & 0.998 & 0.973 & 0.996 \\
\hline 95 & -1.07 & -1.12 & -1.08 & 0.997 & 0.975 & 0.998 \\
\hline 99 & -1.06 & -1.06 & -1.05 & 0.998 & 0.985 & 0.997 \\
\hline 113 & -1.06 & -1.15 & -1.04 & 0.998 & 0.971 & 0.997 \\
\hline 171 & -1.12 & -1.13 & -1.08 & 0.998 & 0.982 & 0.996 \\
\hline$\overline{\mathrm{All}}$ & -1.06 & -1.10 & -1.05 & 0.999 & 0.978 & 0.997 \\
\hline
\end{tabular}

Linear regression was performed with $\mathrm{Ct}$ values vs. $\log _{2}($ ERCC RNA copy number) for each PCR platform across the linear range marked in Figure 1 . The mean slope and $\mathrm{R}^{2}$ values from three independent qPCR experiments reflect the accuracy and precision of the detection of the 10-fold differences in copy numbers between samples. 


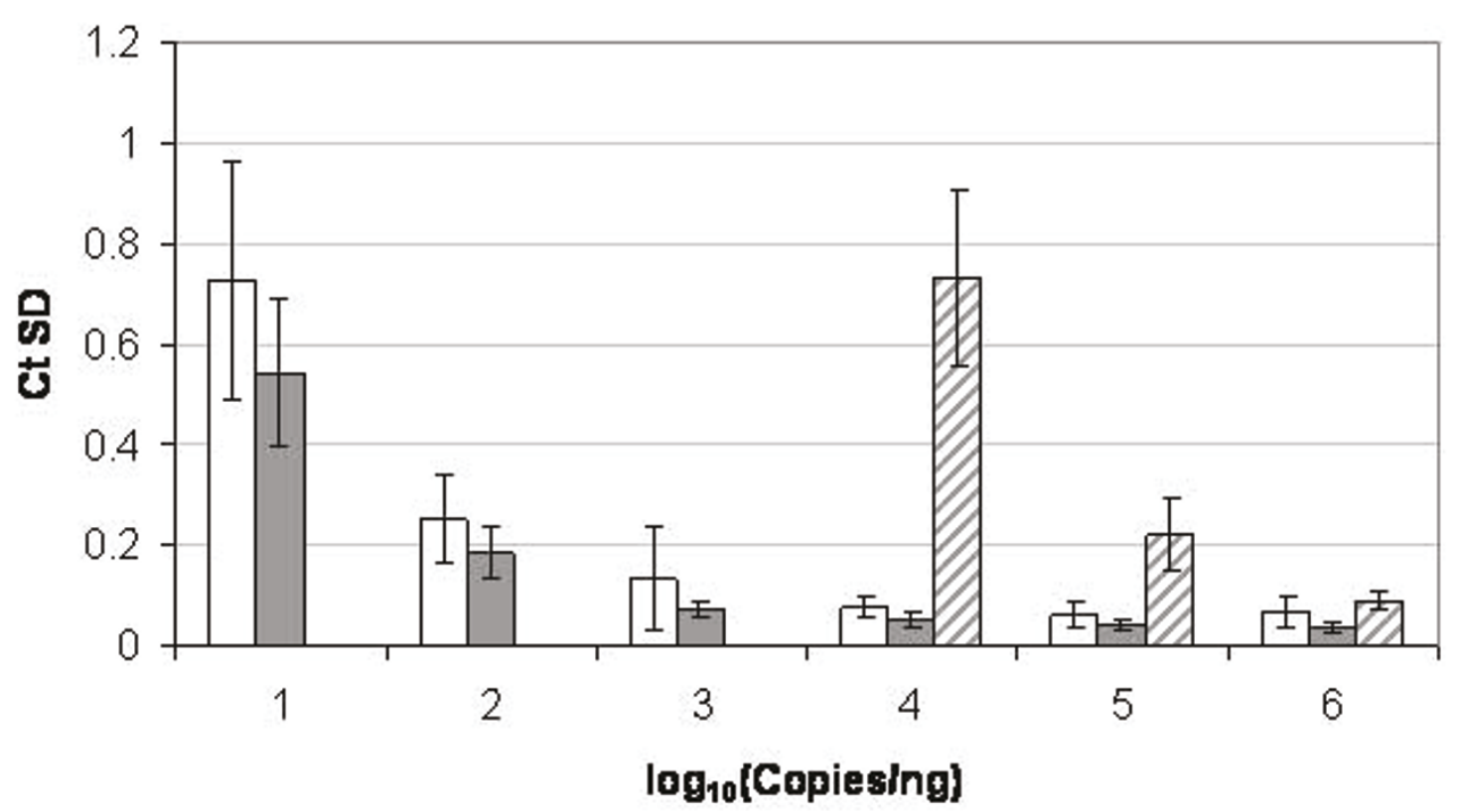

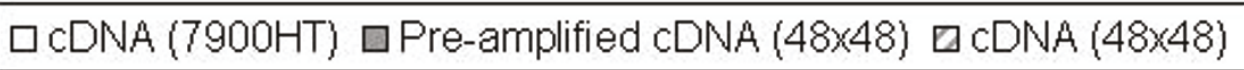

Figure 3 Precision of real-time PCR platforms. Within-run qPCR precision across a range of transcript abundance levels (copies per ng total RNA) are displayed for CDNA or pre-amplified cDNA quantified using ABI 7900HT system or BioMark. Mean variation (SD) of Ct values \pm SD is displayed based on data from eight different RNA standards from three independent qPCR experiments.

unchanged in their expression, standards were spiked at different ratios $(1.0,1.5,2.0,5.0,10.0$ and 20 -fold differences) over a range of transcript copy numbers (Table 2). Three independent RT experiments, each containing two replicate RT reactions, were performed in order to investigate how technical noise associated with the whole RTqPCR process impacts on the detection of differential or non-differential transcript expression levels. The resulting cDNA was quantified on the ABI 7900HT system or pre-amplified and measured on the BioMark. Fold change values were calculated using $\Delta \mathrm{Ct}$ values and the results of pair-wise comparison of the expression levels of each ERCC standard in the two panels displayed in Figure 4.

Overall, fold change estimation was found to be accurate for both ABI 7900HT system and BioMark arrays (Figures 4A and 4B), with the observed fold change values overlapping with the expected fold change measurements for all standards. For ERCC standards mimicking low abundance transcripts, the technical noise associated with the resulting fold change measurement was considerably greater than higher abundance RNA species. For example, a 20 -fold increase in expression level at 5 copies/ng (ERCC-51) is associated with 16-fold and 10 -fold difference in the minimum and maximum fold changes detected by the BioMark arrays and ABI
7900 HT system respectively. For non-differential expression at low copy numbers (fold change $=1.0$; ERCC-113), fold change measurements spanned a range of over $50 \%$ and $150 \%$ of the expected value on the BioMark and ABI $7900 \mathrm{HT}$ system respectively. At levels of abundance exceeding 100 copies/ng, mean fold change measurements were accurate to within $10 \%$ of expected values.

Table 2 Concentrations and ratios of ERCC RNA standards in simulated 'normal' and 'disease' panels

\begin{tabular}{lccc}
\hline ERCC standard & \multicolumn{2}{c}{ Copies/ng total RNA } & Ratio B/A \\
\cline { 2 - 3 } & Panel A & Panel B & \\
\hline 13 & $1 \times 10^{5}$ & $1 \times 10^{5}$ & 1.0 \\
\hline 25 & $1 \times 10^{2}$ & $1.5 \times 10^{2}$ & 1.5 \\
\hline 42 & $1 \times 10^{4}$ & $5 \times 10^{3}$ & 0.5 \\
\hline 51 & $5 \times 10^{0}$ & $1 \times 10^{2}$ & 20.0 \\
\hline 81 & $1 \times 10^{2}$ & $1 \times 10^{2}$ & 1.0 \\
\hline 84 & $1 \times 10^{2}$ & $5 \times 10^{2}$ & 5.0 \\
\hline 95 & $1 \times 10^{3}$ & $1 \times 10^{3}$ & 1.0 \\
\hline 99 & $8 \times 10^{3}$ & $1.2 \times 10^{4}$ & 1.5 \\
\hline 113 & $1 \times 10^{1}$ & $1 \times 10^{1}$ & 1.0 \\
\hline 171 & $1 \times 10^{1}$ & $1 \times 10^{2}$ & 10.0 \\
\hline
\end{tabular}

10 ERCC RNA standards were spiked in a background of Universal Human Reference RNA at different concentrations and ratios in order to create simulated 'normal' and 'disease' panels, A and B. 


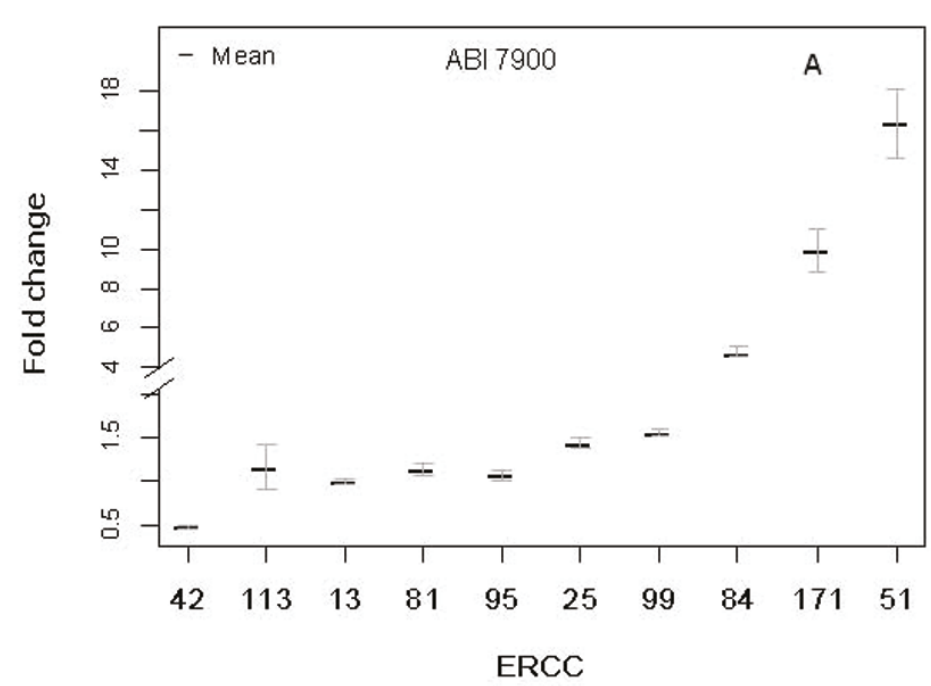

\begin{tabular}{|l|c|c|c|c|c|c|c|c|c|c|}
\hline ERCC & 42 & 113 & 13 & 81 & 95 & 25 & 99 & 84 & 171 & 51 \\
\hline $\begin{array}{l}\text { Expected } \\
\text { FC }\end{array}$ & 0.5 & 1.0 & 1.0 & 1.0 & 1.0 & 1.5 & 1.5 & 5.0 & 10.0 & 20.0 \\
\hline Mean & 0.48 & 1.16 & 0.99 & 1.14 & 1.07 & 1.44 & 1.56 & 4.78 & 9.94 & 16.35 \\
\hline
\end{tabular}

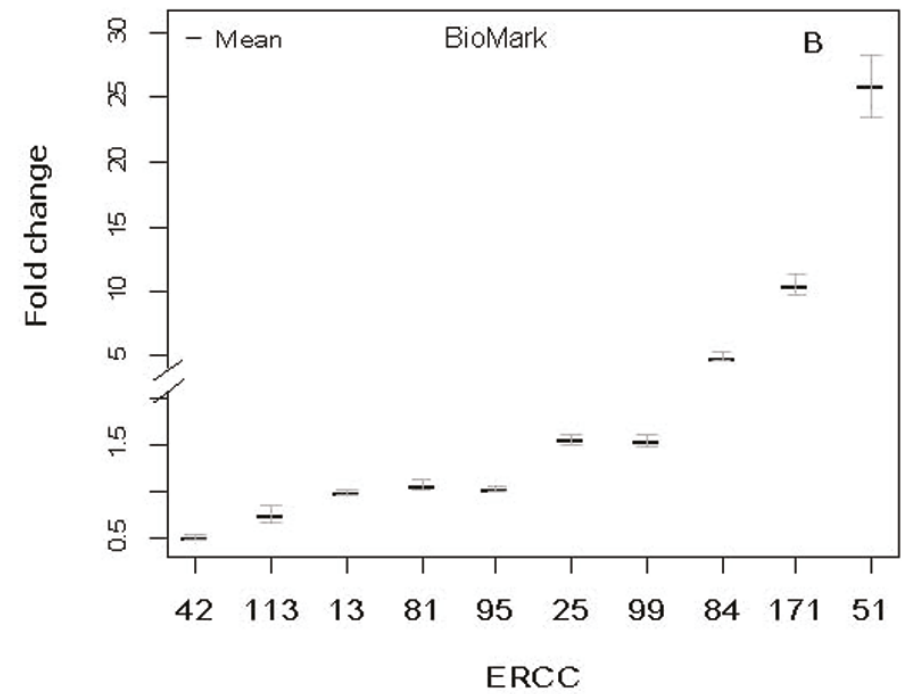

\begin{tabular}{|l|c|c|c|c|c|c|c|c|c|c|}
\hline ERCC & 42 & 113 & 13 & 81 & 95 & 25 & 99 & 84 & 171 & 51 \\
\hline $\begin{array}{l}\text { Expected } \\
\text { FC }\end{array}$ & 0.5 & 1.0 & 1.0 & 1.0 & 1.0 & 1.5 & 1.5 & 5.0 & 10.0 & 20.0 \\
\hline Mean & 0.51 & 0.75 & 0.99 & 1.07 & 1.02 & 1.56 & 1.55 & 4.9 & 10.57 & 25.89 \\
\hline
\end{tabular}

Figure 4 Accuracy of fold change detection. Two panels ( $A$ and B) containing different ratios of RNA standards across a range of copy numbers were quantified using (A) CDNA with the ABI $7900 \mathrm{HT}$ system or (B) pre-amplified cDNA with BioMark $48 \times 48$ dynamic arrays. Expected fold change values (see the tables below the Figures) are compared to the mean of measured fold changes from RT-qPCR reactions performed on six pairs of samples. The error bars represent standard error. 


\section{Discussion}

In this study we sought to demonstrate the utility of RNA standards for characterisation of a new platform, the BioMark, where PCR reactions are performed in volumes over a 1000 -fold lower than on a conventional RT-qPCR instrument (ABI 7900HT system). The requirement for sample pre-amplification for this technology contrasts with standard two-step RT-qPCR approach, therefore the impact of this methodology was also evaluated. Dilutions of RNA standards across a wide physiological range demonstrated that the linear detection range of the BioMark arrays is similar to the ABI 7900HT real-time PCR system, when pre-amplified cDNA is used as the template (Figure 1). The precision of replicate measurements within the array also compared favourably to the intra-run standard deviation of $\mathrm{Ct}$ values for the ABI $7900 \mathrm{HT}$ system (Figure 3). At copy numbers mimicking medium to high abundance transcripts, the precision of the BioMark arrays is in a similar range to the minimum variation of $\sim 0.1$ units observed for another nanofluidic PCR array, the OpenArray format [14].

However, when non-amplified cDNA is quantified using the nanofluidic BioMark arrays, the linear range is severely limited, to only two orders of magnitude (Figure 1). At the lower detection limit of $10^{4}$ RNA copies per reaction $(\mathrm{Ct} \sim 27)$, the variation between measurements increases significantly (Figure 3), whilst below this level of abundance, the rate of PCR failures increases rapidly (Figure 2). Pre-amplification of template cDNA using a preliminary PCR step of 14 cycles improves both the accuracy and precision of the transcript quantification using the dynamic arrays (Table 1). The improved detection of the 10-fold differences in RNA copy numbers between sample series (resulting in an average slope within $6 \%$ of expected value) also indicates that the pre-amplification process does not introduce bias into the detection of transcripts which cover a wide dynamic range.

Relative expression measurements are central to gene expression analysis by RT-qPCR and for determining whether a panel of biomarkers has predictive power for disease diagnosis and prognosis [15]. Therefore, we developed two panels of RNA standards in order to further investigate the accuracy of detecting gene expression ratios using the new type of PCR array compared to an established system. The standards were spiked at varying ratios between panels in order to obtain information on how well the methodologies can discriminate between differentially and non-differentially expressed candidate genes at different transcript abundance levels (Figure 4). Our results show good accuracy of observed $v s$. expected values for both platforms, which is in agreement with previous studies demonstrating good concordance of fold change measurements between the BioMark arrays and the ABI 7900HT system [16]. The precision of the fold change estimation varied according to the abundance of the transcripts, demonstrating increased variation in the observed values for lower concentrations of standards for both nanofluidic and standard real-time PCR approaches. This suggests that the sensitivity of the technique to correctly detect the expected fold change is reduced at low copy numbers (10 RNA copies or less per reaction on the ABI 7900HT system). Dixon et al. [14] also found that the sensitivity of the OpenArray platform was lower for Ct values corresponding to lower copy numbers, resulting in an increased number of false negative results. The increased variation in fold change detection at low copy numbers is likely to arise due to decreased efficiency at RT stage and increased stochastic variation in the PCR reaction for low target numbers [17].

We also found that both qPCR platforms were able to accurately detect a 1.5 -fold change in mRNA expression, below the 2-fold cut-off which has been cited as a limit to the resolving power of conventional PCR, as it constitutes a difference of less than a single cycle [18]. The BioMark dynamic arrays were recently shown to be able to detect a 1.25 -fold difference in DNA copy number by qPCR, with greater levels of precision achievable with the larger number of technical replicates possible with this high-throughput approach [19]. Since assay and sample loadings are in separate inlets on $48 \times 48$ dynamic arrays, it is possible to increase technical replication by using multiple assay inlets and/or multiple sample inlets. However, it should be noted that replication only at the assay level does not substitute for true sampling variation by the process of taking a sample from a population of molecules.

The use of gene-specific oligonucleotide standards for inter-run and cross-platform calibration has been demonstrated to improve the accuracy of class prediction based on panels of biomarkers [15]. Although ERCC RNA standards do not directly provide information on the performance of biomarker-specific assays, a panel of multiple standards, such as that used here provides a robust means of evaluating platform performance by minimizing confounding effects resulting from differences in assay performance due to individual primer and probe specificity. RNA standards could also serve as calibrator samples between experiments where different sets of potential biomarkers genes are investigated, as well as in the context of a diagnostic assay where the expression of the same panel of genes is quantified. In addition to target gene normalization using a reference gene or panel of reference genes [20], normalization to an ERCC RNA standard or multiple RNA standards may be a useful control for elucidating technical variation due to RT and qPCR steps [21]. 


\section{Conclusions}

We conclude that universal RNA standards can provide robust information on the performance characteristics of different RT-qPCR platforms and methodologies. The results obtained using panels of multiple RNA standards indicate that the linear detection range, precision and accuracy of nanofluidic BioMark dynamic arrays are similar to those of an established real-time PCR instrument, the ABI 7900HT system, when pre-amplified cDNA is used as the template. The standards also provide reference values for the range of transcript abundance over which it would be possible to measure non-amplified cDNA on the nanofluidic BioMark highthroughput arrays. Carefully constructed panels of ERCC RNA standards have the potential to act as benchmarks for the calibration and interpretation of biomarker measurements in drug discovery and clinical diagnostics. Further evaluation of these standards is required for potential incorporation into a 'quality metrics' toolkit for assessing their suitability for crossplatform comparisons.

\section{Methods}

\section{Preparation of in vitro transcribed RNA and samples}

In vitro transcribed ERCC RNA standards were produced from ERCC plasmid DNA (courtesy of Dr. Marc Salit, NIST, USA). Plasmid DNA from standards ERCC-13, 25, $42,51,81,84,95,99,113$ and 171 was cleaved into a single linear molecule using $\mathrm{Bam} \mathrm{HI}$ restriction endonuclease (New England Biolabs, UK). 500 ng of plasmid DNA was used for each sample and digested by adding $40 \mathrm{U}$ of BamHI enzyme in NEB3 buffer provided by the manufacturer. The digestion mixture was incubated at $37^{\circ} \mathrm{C}$ for 2 hours followed by purification using QiaQuick PCR purification kit with an elution volume of $32 \mu \mathrm{l}$. In vitro transcription was carried out with $8 \mu$ digested plasmid DNA using MEGAscript ${ }^{\circledR}$ T7 Kit (Applied Biosystems/Ambion, UK) followed by DNase treatment and clean-up using RNeasy columns (Qiagen, UK). RNA concentration and insert sizes were estimated using the Nanodrop 1000 spectrophotometer (Thermo Scientific, UK) and 2100 Bioanalyzer (Agilent Technologies, USA) respectively. RNA standards were diluted in nuclease free-water and spiked into Universal Human Reference RNA (Stratagene, UK) (final concentration $100 \mathrm{ng} / \mu \mathrm{l}$ ). For experiments investigating the linear range of platform detection, standards were spiked at 10 -fold intervals between 1 and $10^{6}$ copies/ ng total RNA (Additional File 2). For the simulated 'normal' and 'disease' panels, standards were spiked at various copy numbers and ratios (Table 2).

\section{Reverse transcription and pre-amplification of cDNA} RNA samples were reverse-transcribed using the Taq$\operatorname{Man}^{\circledR}$ Reverse Transcription Reagents kit (Applied
Biosystems, UK) in $40 \mu \mathrm{L}$ reactions containing $400 \mathrm{ng}$ total RNA and oligo(dT) primers according to manufacturer's instructions. cDNA samples were diluted to a concentration of $0.5 \mathrm{ng} / \mu \mathrm{L}$ (total RNA equivalent) with nuclease-free water. For experiments investigating the linear range of platform detection (Figures 1, 2, 3), a single $\mathrm{RT}$ reaction was performed for each RNA sample whilst for the simulated 'normal' and 'disease' panels (Figure 4), 6 replicate RT reactions were performed. A single aliquot of each cDNA sample, equivalent to $12.5 \mathrm{ng}$ RNA, was pre-amplified with assays corresponding to all 10 standards in a $25 \mu \mathrm{L}$ volume reaction using TaqMan ${ }^{\circledR}$ PreAmp Mastermix (Applied Biosystems, UK) according to manufacturer's protocol. Following pre-amplification, the samples were diluted 1:5 (v/v) in TE buffer, pH 8.0.

\section{Real-time PCR}

Further information on sample preparation and realtime PCR validation complying with the Minimum Information for Publication of Quantitative Real-Time PCR Experiments (MIQE) guidelines [22] is available in Additional Files 2 and 3 (MIQE Additional Information and Checklist).

Custom-designed primers and TaqMan ${ }^{\circledR}$ FAMTAMRA probes for each ERCC standard (Additional File 1) were supplied by Applied Biosystems and a $20 \times$ assay mix was prepared containing $18 \mu \mathrm{M}$ primer and $5 \mu \mathrm{M}$ probe (final concentration $900 \mathrm{nM}$ primer and $250 \mathrm{nM}$ probe). qPCR assays were tested initially using a serial dilution of ERCC CDNA and PCR efficiencies calculated (see Additional Data Table 2: MIQE Additional information). All 10 assays were found to have PCR efficiencies of greater than $86 \%$.

BioMark arrays were prepared according to the manufacturer's instructions. TaqMan ${ }^{\circledR}$ assays were diluted 1:1 $(\mathrm{v} / \mathrm{v})$ with DA Assay Loading Reagent $\left(\right.$ Fluidigm $\left.^{\circledR}\right)$ and $5 \mu \mathrm{L}$ was added to each assay inlet of the array. Also, $5 \mu \mathrm{L}$ reaction mix was prepared by mixing $2 \times$ TaqMan ${ }^{\circledR}$ Universal Mastermix (Applied Biosystems), DA Sample Loading Reagent and nuclease-free water containing $2 \mu \mathrm{L}$ of cDNA or pre-amplified cDNA. The samples were loaded into each sample inlet as per manufacturer's recommendations. Following loading of the assays and samples into the chip by the IFC controller, PCR was performed with the following reactions conditions: $50^{\circ} \mathrm{C}$ for 2 minutes, $95^{\circ} \mathrm{C}$ for 10 minutes, followed by 45 cycles of $95^{\circ} \mathrm{C}$ for 15 seconds and $60^{\circ} \mathrm{C}$ for $60 \mathrm{sec}-$ onds. Data was processed by automatic global threshold setting with the same threshold value for all assays and linear baseline correction using BioMark Real-time PCR Analysis software (version 2.1.1). The quality threshold was set at the default setting of 0.65 . For experiments investigating the linear range of platform detection (Figures 1, 2, 3), 8 qPCR reactions consisting of 4 assay 
inlet and 2 sample inlet replicates were performed for each cDNA or pre-amplified cDNA sample. For the simulated 'normal' and 'disease' panels (Figure 4), 12 qPCR reactions consisting of 4 assay inlet and 3 sample inlet replicates were performed for each cDNA sample.

Conventional real-time PCR was performed using ABI $7900 \mathrm{HT}$ system in $20 \mu \mathrm{L}$ reaction volumes containing TaqMan ${ }^{\circledR}$ Universal PCR Master Mix and $2 \mu \mathrm{L}$ of respective cDNA in optical 96-well plates (Applied Biosystems). Cycling conditions were as those used for the BioMark arrays. Triplicate qPCR reactions were performed for each cDNA sample for all experiments. The threshold fluorescence level was set manually for each plate using SDS software version 2.3 (Applied Biosystems). Following export of Cycle threshold (Ct) data, further data analysis for both platforms was performed in Microsoft ${ }^{\circledR}$ Excel 2003. Comparison of slope and $\mathrm{R}^{2}$ values between pre-amplified and non-amplified cDNA, as a template on the BioMark arrays, was performed as paired $t$-test in Microsoft ${ }^{\circledR}$ Excel 2003.

\section{Additional files}

The following additional are available with the online version of this paper. Additional data file 1 is a table detailing the primer and probe sequences used for qPCR assays. Additional files 2 and 3 are additional data and a checklist in compliance with the MIQE (Minimum Information for Publication of Quantitative RealTime PCR Experiments) guidelines.

\section{Additional material}

Additional file 1: Taqman assays for ERCC RNA standards. Microsoft Word file detailing the sequences of primers and probes used for QPCR assays.

Additional file 2: MIQE Additional Information. Microsoft Excel file containing further information on RNA preparation, purity, PCR efficiency and negative control data complying with the MIQE guidelines.

Additional file 3: MIQE Checklist. Checklist in Microsoft Word format detailing information complying with MIQE guidelines.

\section{List of abbreviations}

ERCC: External RNA Controls Consortium; RT-qPCR: Reverse Transcription Quantitative PCR; LOD: limit of detection; FFPE: formalin-fixed paraffinembedded; IFC: integrated fluidic circuit; RT: Reverse Transcription; PCR: polymerase chain reaction.

\section{Acknowledgements}

The work described in this paper was funded by the UK National Measurement System. We are grateful to Dr. Marc Salit (NIST, USA) for the provision of ERCC plasmid DNA. We would also like to thank Jesus Minguez (LGC) for statistical analysis and Dr. Bridget Fox (LGC) for assistance with the production of in vitro transcribed RNA standards.

\section{Authors' contributions}

AD performed RT-qPCR experiments, participated in the design of the study, performed data analysis and drafted the manuscript. RE participated in the design of the study and helped to draft the manuscript. CF conceived of the study, and participated in its design and coordination and helped to draft the manuscript. All authors read and approved the final manuscript.

Received: 13 October 2010 Accepted: 18 February 2011

Published: 18 February 2011

\section{References}

1. Vermeulen J, Derveaux S, Lefever S, De Smet E, De Preter K, Yigit N, De Paepe A, Pattyn F, Speleman F, Vandesompele J: RNA pre-amplification enables large-scale RT-qPCR gene-expression studies on limiting sample amounts. BMC Res Notes 2009, 2:235.

2. Li J, Smyth P, Cahill S, Denning K, Flavin R, Aherne S, Pirotta M, Guenther SM, O'Leary JJ, Sheils O: Improved RNA quality and TaqMan Pre-amplification method (PreAmp) to enhance expression analysis from formalin fixed paraffin embedded (FFPE) materials. BMC Biotechnol 2008, 8:10.

3. Eberwine J, Yeh $H$, Miyashiro $K$, Cao $Y$, Nair S, Finnell $R$, Zettel M, Coleman P: Analysis of gene expression in single live neurons. Proc Nat Acad Sci USA 1992, 89:3010-3014.

4. Kurn N, Chen P, Heath JD, Kopf-Sill A, Stephens KM, Wang S: Novel isothermal, linear nucleic acid amplification systems for highly multiplexed applications. Clin Chem 2005, 51:1973-1981.

5. Iscove NN, Barbara M, Gu M, Gibson M, Modi C, Winegarden N: Representation is faithfully preserved in global cDNA amplified exponentially from sub-picogram quantities of mRNA. Nat Biotechnol 2002, 20:940-943.

6. Ginsberg SD: RNA amplification strategies for small sample populations. Methods 2005, 37:229-237.

7. Levesque-Sergerie JP, Duquette M, Thibault C, Delbecchi L, Bissonnette N: Detection limits of several commercial reverse transcriptase enzymes: impact on the low- and high-abundance transcript levels assessed by quantitative RT-PCR. BMC Mol Biol 2007, 8:93.

8. External RNA Controls Consortium: Proposed methods for testing and selecting the ERCC external RNA controls. BMC Genomics 2005, 6:150.

9. Baker SC, Bauer SR, Beyer RP, Brenton JD, Bromley B, Burrill J, Causton H, Conley MP, Elespuru R, Fero M, Foy C, Fuscoe J, Gao X, Gerhold DL, Gilles P, Goodsaid F, Guo X, Hackett J, Hockett RD, Ikonomi P, Irizarry RA, Kawasaki ES, Kaysser-Kranich T, Kerr K, Kiser G, Koch WH, Lee KY, Liu C, Liu ZL, Lucas A, et al: The External RNA Controls Consortium: a progress report. Nat Methods 2005, 2:731-734.

10. Cronin M, Ghosh K, Sistare F, Quackenbush J, Vilker V, O'Connell C: Universal RNA Reference Materials for Gene Expression. Clin Chem 2004 50:1464-1471.

11. Ross JS: Multigene classifiers, prognostic factors, and predictors of breast cancer clinical outcome. Adv Anat Pathol 2009, 16:204-215.

12. Clinical and Laboratory Standards Institute: Use of External RNA Controls in Gene Expression Assays. 2010, Approved Guideline 26 No. 29, MM16-A.

13. Stahlberg A, Hakansson J, Xian X, Semb H, Kubista M: Properties of the reverse transcription reaction in mRNA quantification. Clin Chem 2004, 50:509-15.

14. Dixon JM, Lubomirski M, Amaratunga D, Morrison TB, Brenan CJ, Ilyin SE: Nanoliter high-throughput RT-qPCR: a statistical analysis and assessment. Biotechniques 2009, 46:ii-viii.

15. Vermeulen J, Pattyn F, De Preter K, Vercruysse L, Derveaux S, Mestdagh P, Lefever S, Hellemans J, Speleman F, Vandesompele J: External oligonucleotide standards enable cross laboratory comparison and exchange of real-time quantitative PCR data. Nucleic Acids Res 2009, 37: e138.

16. Spurgeon SL, Jones RC, Ramakrishnan R: High throughput gene expression measurement with real time PCR in a microfluidic dynamic array. PLOS One 2008, 3:e1662.

17. Bustin SA, Nolan T: Pitfalls of quantitative real-time reverse-transcription polymerase chain reaction. J Biomol Tech 2004, 15:155-166.

18. Lo YM, Lun FM, Chan KC, Tsui NB, Chong KC, Lau TK, Leung TY, Zee BC, Cantor CR, Chiu RW: Digital PCR for the molecular detection of fetal chromosomal aneuploidy. Proc Natl Acad Sci USA 2007, 104:13116-13121.

19. Weaver S, Dube S, Mir A, Qin J, Sun G, Ramakrishnan R, Jones RC, Livak KJ: Taking qPCR to a higher level: Analysis of CNV reveals the power of high throughput qPCR to enhance quantitative resolution. Methods 2010, 50:271-6.

20. Vandesompele J, De Preter K, Pattyn F, Poppe B, Van Roy N, De Paepe A, Speleman F: Accurate normalization of real-time quantitative RT-PCR 
data by geometric averaging of multiple internal control genes. Genome Biol 2002, 3:RESEARCH0034.

21. Gilsbach R, Kouta M, Bonisch H, Bruss M: Comparison of in vitro and in vivo reference genes for internal standardization of real-time PCR data. Biotechniques 2006, 40:173-177.

22. Bustin SA, Benes V, Garson JA, Hellemans J, Huggett J, Kubista M, Mueller R, Nolan T, Pfaffl MW, Shipley GL, Vandesompele J, Wittwer CT: The MIQE Guidelines: Minimum Information for Publication of Quantitative RealTime PCR Experiments. Clin Chem 2009, 55:611-622.

doi:10.1186/1471-2164-12-118

Cite this article as: Devonshire et al.: Applicability of RNA standards for evaluating RT-qPCR assays and platforms. BMC Genomics 2011 12:118.

Submit your next manuscript to BioMed Central and take full advantage of:

- Convenient online submission

- Thorough peer review

- No space constraints or color figure charges

- Immediate publication on acceptance

- Inclusion in PubMed, CAS, Scopus and Google Scholar

- Research which is freely available for redistribution

Submit your manuscript at www.biomedcentral.com/submit 